\title{
Obstructive sleep apnea: oral appliances and materials
}

Srilekha Cheruku${ }^{1,}{ }^{*}$, Chalapathi Rao Duggineni², Harilal G ${ }^{3}$, Pavani Lukka4

${ }^{1}$ Postgraduate Student, 2 Professor, ${ }^{3}$ Reader, ${ }^{4}$ Senior Lecturer Mamata Dental College, Giri Prasaad Nagar,

Khammam, Telangana, India -507002.

\section{N F O R M A T I O $\mathrm{N}$ A B S T R A C T}

\section{Article History}

Received 15 ${ }^{\text {th }}$ March 2021

Accepted 3rd May 2021

Available online

$15^{\text {th }}$ May 2021

\section{K E Y W O R D S}

Sleep apnea,

Hypopnea,

Prosthodontic management

Oral appliances
For the dental profession in general and in prosthodontists speciality, the subject of sleep medicine continues to offer great challenges and opportunities in diagnosis, treatment planning, and treatment based on qualitative evidence. Though the role contends by the prosthodontists is still in its infancy, there is a lot to find out and understand in the rapidly evolving field of sleep medicine because the recognition of co-managing patients with sleep disorders by the prosthodontists is quick changing into a reality. This article discusses the prosthodontic perspectives, particularly on obstructive sleep apnea.

\section{Introduction}

Obstructive sleep apnea has become more common nowadays. It is the most common respiratory disease associated with chronic insomnia. OSA causes a partial or complete narrowing of the upper airway during sleep by stopping/ reducing airflow, leading to regular sleep disturbances [1]. The different varieties of sleep apnea are obstructive, central and mixed. Obstructive is the most common of all three [2]. The role of prosthodontics is becoming more significant in treating sleep disorders especially in patients with mild to moderate obstructive sleep apnea (OSA). This article describes the epidemiology, etiology, pathophysiology, clinical features, and types of oral appliances used to treat obstructive sleep apnea.

\section{Epidemiology}

It has been reported that $10 \%$ and $5 \%$ of men and women, respectively, in the 30-40-year age group are common snorers, reaching at least $20 \%$ for males and $15 \%$ for females in the 50-60 year age group. It has been reported that $5 \%$ of the world population is affected by OSA, with the prevalence of $4 \%$ for men and $2 \%$ for women in the aged of 30-60 years [1,3-5].

\section{Predisposing factors}

Obesity is an important risk factor with prevalence ranging from 55 to $100 \%$ [6]. Craniofacial abnormalities like micrognathia, retrognathia, enlarged palatine tonsils, enlarged uvula, high arched palate, nasal deviation, longer anterior facial height, enlarged tongue, long soft palate, decreased posterior airway space. In addition to age, genetic, ethnic and gender predilection and various habits such as alcohol consumption, smoking and drugs use, the existing OSA is aggravated [7].

4. Pathophysiology 
The upper airway is a soft tissue tube, the patency of which is maintained, in part, by muscles such as tensor veli and genioglossus. The base of the tongue obstructs the upper airway resulting in snoring. The upper airway is composed of the nasopharynx, oropharynx, and hypopharynx. When the patient falls asleep in the supine position, muscle relaxation causes the base of the tongue to approach the posterior wall of the pharynx. With the consequent reduction of airflow, the patient must increase the airflow speed to maintain the required oxygen supply to the lungs. This increase in airflow velocity causes the vibration of soft tissues that produces snoring.

The total volume of fat has been shown to be greater in OSA patients. Increase in thickness of the lateral pharyngeal wall predisposed to OSA development $[7,8]$. The various clinical symptoms observed in patients with OSA presented in Table 1 [9-14].

\section{Diagnosis}

Diagnosis of OSA can be made on history, examination, polysomnography [15], lateral cephalograms, computed tomography scanning, acoustic reflection test, limited channel testing and oximetry $[16,17]$.

The severity of OSA is classified based on the patient's AHI (APNEA-HYPOPNEA INDEX) index. It is the average number of disordered breathing events per hour $[5,18,19]$. They include mild OSA (5 to 15 events per hour), moderate OSA (15 to 30 events per hour), and Severe OSA (more than 30 events per hour).

\section{Treatment}

OSA therapies include behavioural modification, positive air pressure (continuous positive airway pressure), oral and surgical procedures [20]. Oral appliances are widely used in patients with mild to moderate apnea.

\section{Rationale behind using oral appliances}

Oral appliances are worn solely during sleep and work to enlarge the airway by moving the tongue anteriorly or the mandible to enlarge the airway. Oral appliances help in preventing the tongue from blocking the throat, and/or pushing the mandible forward is often done. These devices help to keep the airway open during sleep. Proposed mechanisms for the action of oral appliances include increased upper airway size, decreased upper airway collapsibility, activation of upper airway dilator muscles, and stabilization of mandibular posture [21,22].

\section{Materials used for fabricating oral appliances}

Two different materials used for the fabrication of oral appliances, such as hard acrylics and thermal acrylics.

\subsection{Hard acrylics}

Hard acrylics are either chemically or heat processed, resulting in hard and rigid tooth-borne and occlusal surfaces. These are the common materials for fabricating oral appliances. They can be adjusted or repaired chair side easily without the need for an entirely new appliance and are easy to insert and remove. Hard acrylic appliances are more retentive when the shape of the clinical crown has good undercuts. Clasps can be used for additional retention.

Acrylic resins are known as PMMA which can be packed or injected into moulds and solidifies through a chemical reaction of polymerization. The disadvantages of heat-cured acrylic resins connected to increased porosity, high water retention, volume variations, and irritating effect of the residual monomer have led to alternative materials such as polycarbonate resins and polyamides, acetal resins and epoxy resins $[23,24]$.

\subsection{Thermal acrylics}

They are soft and pliable at a warm temperature. Thermal acrylics allow comfort and easy seating, minimize the occlusal derangement. The major drawback of this

Table 1. Clinical features of obstructive sleep apnea [9-14]

- Memory problems

- Excessive day time sleepiness

- Difficulty in concentrating

- Night drooling of saliva

- Depression

- Irritability

- Xerostomia

- $\quad$ Gasping for breath at night and witnessed apneas.

- Poor work performance

- Occupational accidents 
materials is it requires more frequent replacement than hard acrylics, especially for bruxers. They are manufactured through the thermoforming procedure from Essix type-A co-polyester or polypropylene copolymer [24].

\section{Oral appliances}

Oral appliances were first referred to in 1923 in books by the French paediatrician Pierre Robin [25], who described the fall of the tongue base as a cause of nasopharyngeal impairment and suggested a prosthesis to correct "dysmorphic atresia of the mandible".

However, these devices were not used in the treatment of sleep apnea until the early 1980s. They were started using after describing a tongue retaining device to treat snoring and apnea by Cartwright and Samelson [26]. A renewed interest followed this device in mandibular development devices (MADs) that re-positioned the mandible in the protrusive position to help maintain the patency of the upper airway during sleep.

There are currently more than 55 oral appliances on the market. The appliances can be broadly classified into the following 4 types.

a. Tongue re-positioning devices, such as the tongue retaining device.

b. Mandibular advancement devices (MAD) work by holding the lower jaw and the tongue forward during sleep.

c. Devices designed to lift the soft palate.

d. Uvula lifters, which are not in use now due to discomfort.

\subsection{Soft palate lifting}

The soft palate lifting prosthesis lifts and/or stabilizes the soft palate, preventing vibration during sleep. The palatal lift prosthesis significantly improved the upper airway passage and eliminated snoring and airway obstruction, and improved the patient's overall quality of life [27].

\subsection{Mandibular repositioning devices}

It advances the mandible, brings forward the tongue and other muscles of the pharynx and elevates the palato-glossus muscle; thus, airway patency is enhanced. It also holds the mandible and other structures in a stable position to prevent the mouth opening. This is usually the most widely used respiratory device for apnea and has a higher evidence base. The devices cover the upper and lower arch and have metal hinges. The mandibular advancement device requires good retention, sufficient protrusion to maintain airway, minimal vertical opening, and full occlusal coverage.

\subsubsection{Disadvantages}

Reduced effectiveness in patients with: TMJ, myofascial pain, tooth tenderness, excessive salivation, gum irritation and bleeding, dry mouth and edentulous patients. Long-term MAD use may lead to dental and skeletal side effects that include [28]:

- Decrease in overjet and overbite

- Retroclination of maxillary incisors

- Proclination of mandibular incisors

- Increase in the mandibular plane angle

- Increases in anterior facial height

- Decrease in the number of occlusal contact points

- Anteroposterior change in occlusion.

When MAD is used, the teeth should be free from caries and periodically healthy and sound teeth to withstand the displacement forces.

\subsection{Klearway oral appliance}

The Klearway oral appliance uses a maxillary orthodontic expander to move the mandible forward sequentially. Klearway is a fully adjustable oral appliance used for snoring and mild to moderate OSA. A Small increase in mandibular advancement is initiated by the patient, preventing rapid jaw movements that cause significant patient discomfort (Figure 1) [29].

\subsection{PM positioner}

This appliance links the upper and lower splints with bilateral orthodontic expanders. This appliance is made of thermoplastic material (Figure 2) that must be heated in hot tap water every night before it is placed in the mouth [30].

\subsection{The Thornton adjustable positioner (TAP)}

This enables the progressive ' $0 \mathrm{~mm}$ advancements of the jaw through the anterior screw mechanism at the labial aspect of the upper splint. This appliance has a separate section for both the mandible and maxillary (Figure 3) [31].

\subsection{Modified Herbst Appliance}

This design links the upper and lower splints with a piston-post and the adjustable telescopic mechanism on both sides. It prevents side-to-side motion, but 

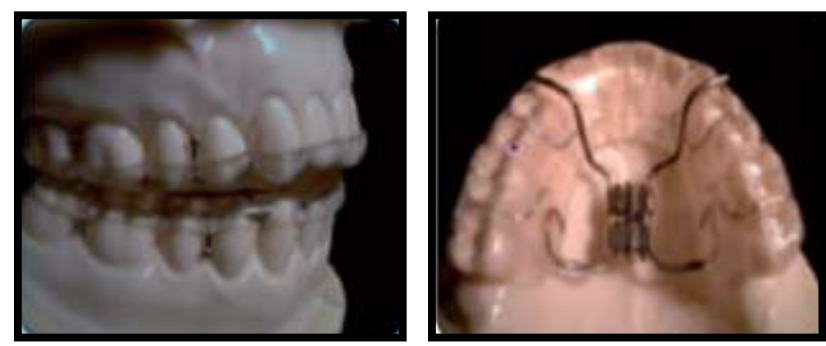

Figure1. Klearway appliance
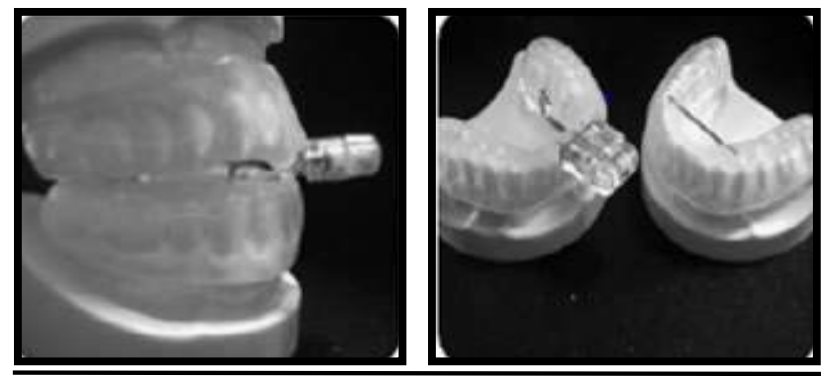

Figure 3. Thornton adjustable positioner



Figure 2. PM positioner

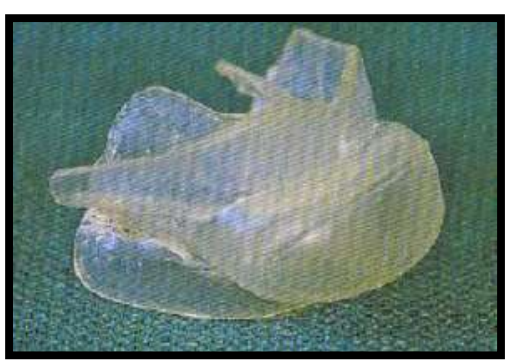

Figure 4. Tongue retaining device since the mandible is kept close with small orthodontic rubber bands, opening the jaws is relatively easy $[32,33]$.

\subsection{The silencer system}

This incorporates titanium precision attachments at the incisor level, allowing sequential $2 \mathrm{~mm}$ advancement of up to $8 \mathrm{~mm}$, lateral movement of $6 \mathrm{~mm},(3 \mathrm{~mm}$ bilaterally) and vertical pin height replacements. It is the only appliance that enables anteroposteriorly adjustment and an open and closed position since it includes a very expensive titanium metal hinge device $[34,35]$.

\subsection{Tongue retaining device (TRD)}

It was first developed in 1979. It is a bubble-shaped device. TRD operates by holding the tongue in a forward position utilizing a suction bulb, which keeps the tongue from collapsing during sleep and obstructing the airway inside the throat. TRD is an excellent tool for patients or those suffering from TMJ sensitivity. This is usually a single piece of non-vinyl material without thermoplastic material to adapt to the teeth. Retention to the teeth or residual ridges is not a requirement with this device, and thus the rigidity of the device is unnecessary (Figure 4) [25]. These devices are indicated for edentulous patients, and patients with potential temporomandibular joint problems. TRDs do not require retention from dentition, Minimal adjustments are required, Cause minimal sensitivity to teeth and TMJ.

\subsection{Side effects and complications}

Dental malocclusion (21\%), TMJ pain (15\%), and TMJ dislocation $(<5 \%)$, excessive salivation, tooth pain, posterior open bite are side effects of MRD. The overall incidence of side effects with MRDs is 25-60\% which can be resolved with device adjustment.

Tongue abrasion, excessive salivation, and gagging are some of the TRD's reactions. The overall incidence of side effects for TRD was $25-75 \%$. Recalls are necessary at a minimum of two weeks, one month, and after that every six months. These appliances are retained tightly by the remaining dentition and place almost orthodontic like forces on the teeth. They may also become loose or distort, or break, and hence maintenance is mandatory [36,37].

\section{Conclusion}

The oral appliances used to date form a group of heterogeneous devices used in the treatment of sleep apnea. Current evidence suggests that oral appliances "cure" mild to moderate sleep apnea in $40-50 \%$ of patients and significantly improved by $10-20 \%$. A prosthodontist should have a vital role in the initial diagnosis, management, and care of patients with sleep apnea. Oral appliances play a crucial role in managing non-surgical OSA and have become the first line of treatment for almost all patients with OSA. 
Conflicts of interest: Authors declared no conflicts of interest.

\section{Financial support: None}

\section{References}

1. Friedman M. Sleep apnea and snoring: Surgical and nonsurgical therapy. Saunders; 2008(2);1-10. https:// doi.org/10.1016/B978-1-4160-3112-3.00001-2

2. Dhingra PL, Dhingra S. Diseases of Ear, Nose and Throat-eBook. Elsevier India; 2014 Oct 10:277.

3. Young T, Skatrud J, Peppard PE. Risk factors for obstructive sleep apnea in adults. JAMA. 2004;291 (16):2013-6. https://doi.org/10.1001/jama.291.16.2013

4. Padma A, Ramakrishnan N, Narayanan V. Management of obstructive sleep apnea: A dental perspective. Ind J Dent Res. 2007;18(4):201. https://doi.org/10.4103/0970-9290.35833

5. Chandra SD, Raj KS, Prema et al. Obstructive sleep apnea and its prosthodontic management- an overview. Int J Health Sci Res. 2018; 8(3):259-265.

6. Garg R, Singh A, Prasad R, Saheer S, Jabeed P, Verma R. A comparative study on the clinical and polysomnographic pattern of obstructive sleep apnea among obese and non-obese subjects. Ann Thorac Med. 2012;7(1):26. https://doi.org/10.4103/1817-1737.91561

7. Young T, Peppard PE, Gottlieb DJ. Epidemiology of obstructive sleep apnea: a population health perspective. Am J Respir Crit Care Med. 2002;165(9):121739. https://doi.org/10.1164/rccm.2109080

8. Schwab RJ, Gupta KB, Gefter WB, Metzger LJ, Hoffman EA, Pack AI. Upper airway and soft tissue anatomy in normal subjects and patients with sleepdisordered breathing. Significance of the lateral pharyngeal walls. Am J Respir Crit Care Med. 1995;152 (5):1673-89.

https://doi.org/10.1164/ajrccm.152.5.7582313

9. Caples SM, Somers VK. Obstructive Sleep Apnea and Stroke. Ann. Intern. Med. 2005;143(5):390. https://doi.org/10.7326/0003-4819-143-5-200509060$\underline{00017}$

10. Deberry-Borowiecki B, Kukwa A, Blanks RH. Cephalometric analysis for diagnosis and treatment of obstructive sleep apnea. The Laryngoscope. 1988;98 (2):226-34.

https://doi.org/10.1288/00005537-198802000-00021

11. Imes NK, Orr WC, Smith RO, Rogers RM. Retrognathia and sleep apnea: a life-threatening condition masquerading as narcolepsy. JAMA. 1977;237(15):15967. https://doi.org/10.1001/jama.237.15.1596

12. Miles PG, Vig PS, Weyant RJ, Forrest TD, Rockette Jr HE. Craniofacial structure and obstructive sleep apnea syndrome - a qualitative analysis and meta-analysis of the literature. Am J Orthodont Dentofac Orthoped. 1996;109(2):163-72. https:// doi.org/10.1016/S0889-5406(96)70177-4

13. Strohl KP, Redline S. Recognition of obstructive sleep apnea. Am J Resp Critic Care Med. 1996;154 (2):279-89. https://doi.org/10.1164/ ajrccm.154.2.8756795

14. Tregear S, Reston J, Schoelles K, Phillips B. Obstructive sleep apnea and risk of motor vehicle crash: systematic review and meta-analysis. J Clin Sleep Med. 2009;5(6):573-81. https://doi.org/10.5664/jcsm.27662

15. Chervin RD, Murman DL, Malow BA, Totten V. Cost-utility of three approaches to the diagnosis of sleep apnea: polysomnography, home testing, and empirical therapy. Anna Int Med. 1999;130(6):496505. $\quad$ https://doi.org/10.7326/0003-4819-130-6199903160-00006

16. Chiner E, Signes-Costa J, Arriero JM, Marco J, Fuentes I, Sergado A. Nocturnal oximetry for the diagnosis of the sleep apnoea hypopnoea syndrome: a method to reduce the number of polysomnographies. Thorax. 1999;54(11):968-71. https://doi.org/10.1136/ thx.54.11.968

17. Li HY, Engleman H, Hsu CY, Izci B, Vennelle M, Cross M, Douglas NJ. Acoustic reflection for nasal airway measurement in patients with obstructive sleep apnea-hypopnea syndrome. Sleep. 2005;28(12):15549. https://doi.org/10.1093/sleep/28.12.1554

18. Sandeep C, Gopinadh A, Babu MS, Ravuri K. Revival of the eclipsed: The 5 th dimension of a prosthodontist. Int. J. Dent. Clin. 2011;3(1):71-4.

19. Qureshi A, Ballard RD, Nelson HS. Obstructive sleep apnea. J. Allergy Clin. Immunol.. 2003;112(4):64351. https://doi.org/10.1016/j.jaci.2003.08.031

20. Sunitha C, Kumar SA. Obstructive sleep apnea and its management. Ind J Dent Res. 2010;21(1):119. https:// doi.org/10.4103/0970-9290.62806

21. Wang W, Di C, Mona S, Wang L, Hans M. Tongue Function: An Underrecognized Component in the Treatment of Obstructive Sleep Apnea with Mandibular Repositioning Appliance. Can Respir J. 2018;2018. https://doi.org/10.1155/2018/2157974

22. Rogers RR. Oral appliance therapy for the management of sleep disordered breathing. Sleep Breath 2000;4:79-84. https://doi.org/10.1007/BF03045027

23. Vitalariu A, Tatarciuc M, Diaconu D, Checherita LE. Acrylic Coustom Made Oral Appliances in Obstructive Sleep Apnea Therapy. Revista Materiale Plastice. 2015;52(2):204-8.

24. Cilil VR, Varma NS, Gopinath S, Ajith VV. Efficacy of custom made oral appliance for treatment of obstructive sleep apnea. Contemp Clin Dent. 2015;6 (3):341. https://doi.org/10.4103/0976-237X.161881

25. Robin P. A fall of the base of the tongue considered as a new cause of nasopharyngeal respiratory impairment: Pierre Robin sequence, a translation. 1923. Plast Reconstr Surg 1994;93(6):1301-3. 
26. Cartwright RD, Samelson CF. The effects of a nonsurgical treatment for obstructive sleep apnea: the tongue-retaining device. JAMA. 1982;248(6):705-9. https://doi.org/10.1001/jama.248.6.705

27. Bhalla G, Arya D, Chand P, Singh K, Tripathi S. Management of obstructive sleep apnea with a palatal lift prosthesis. International journal of Stomatology and Occlusion Medicine. 2013;6(3):101-5. https://doi.org/10.1007/s12548-013-0088-5

28. Doff MH, Finnema KJ, Hoekema A, et al. Long-term oral appliance therapy in obstructive sleep apnea syndrome: a controlled study on dental side effects. Clin Oral Investig 2013;17(2):475-82. https://doi.org/10.1007/s00784-012-0737-x

29. Lowe AA. Titratable oral appliances for the treatment of snoring and obstructive sleep apnea. J Can Dent Assoc 1999;65:571-4.

30. Giannasi LC, de Mattos LC, Magini M, Costa MS, de Oliveira CS, de Oliveira LV. The impact of the Adjustable PM Positioner appliance in the treatment of obstructive sleep apnoea. Archiv Med Sci. 2008;4 (3):336.

31. Thornton WK, Roberts DH. Nonsurgical management of the obstructive sleep apnea patient. J Oral Maxillofac Surg. 1996;54(9):1103-8. https://doi.org/10.1016/S0278-2391(96)90170-6

32. Eveloff SE, Rosenberg CL, Carlisle CC, Millman RP. Efficacy of a Herbst mandibular advancement device in obstructive sleep apnea. Am J Respir Critic Care Med. 1994;149(4):905-9. https://doi.org/10.1164/ajrccm.149.4.8143054

33. Itzhaki S, Dorchin H, Clark G, Lavie L, Lavie P, Pillar G. The effects of 1-year treatment with a herbst mandibular advancement splint on obstructive sleep apnea, oxidative stress, and endothelial function. Chest. 2007;131(3):740-9.

https://doi.org/10.1378/chest.06-0965

34. Wade PS. Oral Appliance Therapy for Snoring and Sleep Apnea: Preliminary Report on 86 Patients with an Anterior Mandibular Positioning Device, The Silencer. Journal of Otolaryngology. 2003;32(2). https://doi.org/10.2310/7070.2003.37144

35. Schönhofer B, Stoohs RA, Rager H, Wenzel M, Wenzel G, Köhler D. A novel tongue advancement technique for obstructive sleep apnea and snoring: Side effects and efficacy. Am J Respir Crit Care Med. 1997;155:732-8.

https://doi.org/10.1164/ajrccm.155.2.9032220

36. Loube DI. Oral appliance treatment for obstructive sleep apnea. Clinical Pulmonary Medicine. 1998;5 (2):124-8.

https://doi.org/10.1097/00045413-199803000-00007

37. Ivanhoe JR. Treatment of upper airway sleep disorder patients with dental devices. Clinical Maxillofacial Prosthetics. Quintessence: Chicago. 2000:21531. 